\title{
Morphing wing models analysis and synthesis for the sustainable aeronautics industry
}

\section{Análisis y síntesis de modelos de alas tipo morphing para la industria de aeronáutica sostenible}

\author{
SANDOVAL-MARCELINO, Andres Mariano†, CRUZ-GÓMEZ, Marco Antonio*, MEJÍA-PEREZ, \\ José Alfredo and TEUTLI-LEÓN, Margarita
}

\begin{abstract}
Benemérita Universidad Autónoma de Puebla; Faculty of Engineering, Tribology and Transportation Group, Academic Body 189 (Disaster Prevention and Sustainable Development, Tribology, BUAP), Graduate Building, First Level, Cubicle No. 16, Blvd. Valsequillo esq. Av. San Claudio, Ciudad Universitaria, Col. San Manuel, CP. 72570, Puebla México
\end{abstract} ID $1^{\text {st }}$ Author: Andres Mariano, Sandoval- Marcelino / ORC ID: 0000-0003-4376-3190, Researcher ID Thomson: AAG-
1788-2021, CVU CONACYT ID: 1107441

ID $1^{\text {st }}$ Co-author: Marco Antonio, Cruz-Gómez / ORC ID: 0000-0003-10918133, Researcher ID Thomson: S-3098-2018, CVU CONACYT ID: 349626

ID $2^{\text {nd }}$ Co-author: José Alfredo, Mejía-Pérez / ORC ID: 0000-0002-4090-8828, Researcher ID Thomson: G-3354-2019, CVU CONACYT ID:

ID $3^{\text {rd }}$ Co-author: Margarita, Teutli-León / ORC ID: 0000-0002-8799-8891, Researcher ID Thomson: AAL-848121, CVU CONACYT ID: 120326

DOI: $10.35429 / J R E .2021 .14 .5 .22 .29$

Received April 03, 2021; Accepted June 30, 2021

\begin{abstract}
The morphing type wings aim is to improve their aerodynamic performance in each flight condition as a bird would do it, this improvement is obtained by modifying its shape through intelligent mechanisms. Optimizing and dynamically adapting the shape of the wings to various flight conditions, leads to many unexplored possibilities for improvement that have been identified beyond current model test demonstrations. This research aimed to analyze the most prominent examples of morphing concepts in models of previous wing experimentation. Morphing concepts have certain limitations on a large scale, however some consortia have chosen to investigate it, in full-scale models. In this work, a mixed type methodology is presented covering qualitative and quantitative research studies on morphing-type wings. Finally, it is mentioned the importance of continuing to investigate these models and it is considered that the implementation of real models will aid to optimize the conditions leading to sustainable development models.
\end{abstract}

Morphing, Aeronautical industry, Wing modeling

\begin{abstract}
Resumen
Las alas tipo morphing tienen como objetivo mejorar su rendimiento aerodinámico en cada condición de vuelo como lo haría un ave, esto se obtiene a través de mecanismos inteligentes que modifican la forma de esta. $\mathrm{Al}$ optimizar y adaptar dinámicamente la forma de las alas a las diversas condiciones de vuelo, se ha identificado la existencia muchas posibilidades de mejora sin explorar más allá de las demostraciones actuales de prueba en modelos. Esta investigación tuvo como objetivo analizar los ejemplos más destacados de conceptos morphing en modelos de experimentación previa de alas. Los conceptos morphing tienen ciertas limitaciones a gran escala sin embargo algunos consorcios han optado por investigar en modelos a escala real. En este trabajo se presenta una metodología de tipo mixta que abarca trabajos cualitativos y cuantitativos de investigaciones de alas de tipo morphing. Finalmente se menciona la importancia de seguir investigando estos modelos y se considera que la implementación de estos modelos reales debido a que optimizan las condiciones de modelos de desarrollo sustentables.
\end{abstract}

Morphing, Industria aeronáutica, Modelado de ala

Citation: SANDOVAL-MARCELINO, Andres Mariano, CRUZ-GÓMEZ, Marco Antonio, MEJÍA-PEREZ, José Alfredo and TEUTLI-LEÓN, Margarita. Morphing wing models analysis and synthesis for the sustainable aeronautics industry. Journal Renewable Energy. 2021. 5-14: 22-29

\footnotetext{
* Author Correspondence (e-mail: andres.sandoval@alumno.buap.mx)

$\uparrow$ Researcher contributing as first author.
} 


\section{Introduction}

The word morph comes from the Greek "morphos" which means form. The idea under a Morphing Wing is to obtain the best possible performance by adapting its aerodynamic shape to each flight condition, in aspects like: autonomy, control of the aircraft and its phases during flight etc. The purpose is having a fleet of a single morphing type aircraft with the capacity of being used in different flight conditions and it is more profitable than having a fleet of aircraft being designed for one specific function. $\mathrm{Li}, \mathrm{D}$. et. al, (2018).

Research on morphing wing models is extensive, and they were based on mechanisms of material or shape Min, Z. et. al. (2010), Sofla, A. et. al. (2010) and Sinapius, M. et. al. (2014), some references classify the wings based on the change in geometry Monner, H. et. al. (2012), and Dayyani, I. et. al. (2013) or special materials Dayyani, I. et. al (2013) while others classified them with respect to the concept applied, that is, the transformation in the angle of landing or departure, Monner, H. et. al. (2012) the wingspan configuration Arena, M. et. al. (2019) and $\mathrm{Gu}, X$. et. al. (2020), and a few authors have focused on using these applications in unmanned aircraft models Jenett, B. et. al. (2017), Siddall, R.et. al. (2017). The use of softwares and use of control models are also shown in previous works. Colorado, J. et. al. (2013), the "H1" controller is an example of a robust control system Yue, T. et. al. (2013).

The present research aims to identify the modeling and analysis methods (structure, aerodynamics, control and optimization) with morphing wing applications, a mixed type methodology was used in which previous works that use qualitative and quantitative data were used. The use of these morphing wing models by the industry represents a major advance.

\section{Morphing model research methodology}

This research has a mixed-type approach that works with quantitative and qualitative data including work on aerodynamic models and morphing wing concepts, in which software and experimental tests are used to obtain data about improvement in aerodynamic performance. Comparison between results of tests and the estimated values were obtained in previous works.
A number of improvements that can be implemented are described (flight control, performance, weight, autonomy) these have given novel concepts which are being tested on unmanned aerial vehicle models.

A sampling of morphing wings allowed classified them according to the change in geometry, the variation of wingspan, the angle of attack and departure, etc. In which the main parameters are flight control, performance, weight, autonomy, coefficients of resistance and lift, etc. The previous mentioned models quantify variables such as Von Mises, shear stresses, resistance to linear and turbulent flows, deformations. This mixed method determined a morphing type wing that has been evolving through different approaches, promoting mass reduction, better mobility and better control in each flight phase, storage optimization.

\section{Morphing wings concepts}

A brief review of morphing wings fundamentals was made, since they are applied in configurations at aerodynamic level (2D) and wing level (3D), the concepts related for 2D test cases are variable curvature and thickness, while for the 3D configurations they are the variable extension, wing folding mechanisms, modifying the sweep and the wingspan of the wing to optimize its performance in different flight conditions such as takeoff, cruise and landing.

Specific transformation concepts for design problems, highlighting the multiple solutions, are developed in response to common design drivers (performance, flight control and roll etc.) Transformation concepts are classified into three levels of morphing: low, medium and high, the level of morphing depends on the complexity of the design to be used, that is, as more variables are analyzed together, the higher the level of morphing Li, D. et. al. (2018).

The transformation in the leading edge normally uses mechanisms named "slats" (aerodynamic surfaces that are placed in the attack area and when deployed allow the wing to operate at a greater angle of attack) which are deployed to achieve a higher coefficient of lift than the one that can be achieved in a clean wing configuration (configuration exerted when an aircraft retracts its external gear to minimize air resistance). 
Figure 1 shows the intelligent configuration "Smart droop-nose", SADE (Smart High Lift Devices for Next Generation Wings), it was investigated an intelligent nose configuration on the wing, replacing the conventional slats with a flange edge smart attack Monner, H. et. al. (2012). The experimental and simulations tests carried out for the wing segment in 3D were useful for determining a feasible concept and design method. Identifying deviations from the desired shape which were attributed to manufacturing tolerances Monner, H. et. al. (2012).

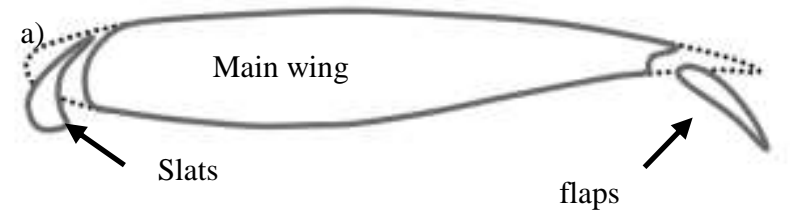

b)

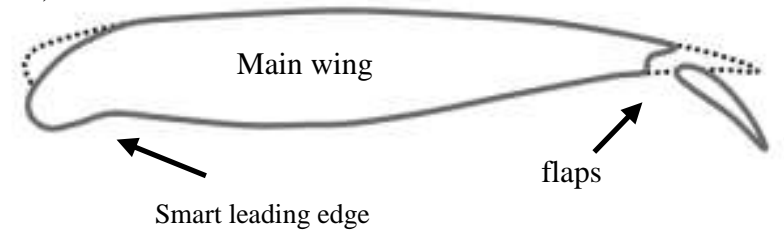

Figure 1 a) Conventional configuration, b) Smart droop configuration Monner, H. et. al. (2012)

Flexible ribs were made by combining separate plate-like elements with angular joints. Due to this construction, the design is called "finger concept", it replaces the inflexible ribs of a conventional flap, with ribs of flexible design as shown in figure 2 Monner, H. et. al. (2001).

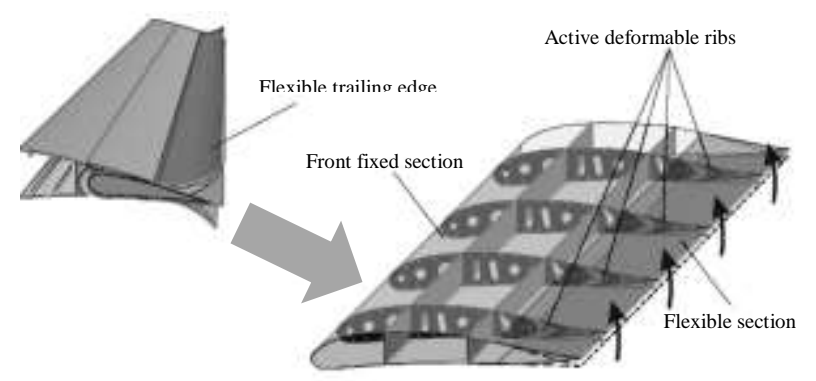

Figure 2 Position and design of active deformable ribs in the "Flower flap" Monner, H. et. al. (2001)

Only one actuator is necessary to deform the rib up or down, however by using a transmission beam it is possible to group ribs so that two actuators work over five ribs, significantly reducing the number of actuators. Li, D. et. al. (2018).
In a variable curvature aerodynamic profile, which presents an integrated design and topology optimization for a morphing wing driven by shape memory ribs (figure 3), a configuration which allows smooth, continuous and precise geometric shape changes by optimizing the wing design through actuators and the wing topology it is obtained $G u, X$. et. al. (2020).

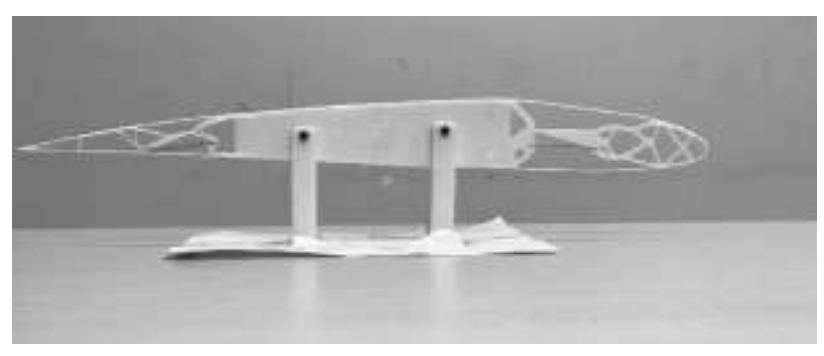

Figure 3 Variable curvature morphing wing model cross section using shape memory ribs. Gu, X. et. al. (2020).

The project "SARISTU" (Smart intelligent Aircraft Structures) is a project that was intended to develop technologies to make a morphing type wing for the general performance of the aircraft, within this the Adaptive Trailing Edge Device (ATED) was developed, this is a device located on the trailing edge which allows the reduction of operational fuel consumption by either pursuing the minimum drag effect or by reducing the overall weight of the aircraft through a load redistribution, the trailing edges with a transformation adaptive systems offer improved fuel efficiency in commercial transport aircraft. The SARITU project used adaptive wing systems on board large commercial aircraft Arena, M. et. al. (2019).

A flap (it is a hyper-lift device, functioning as its name indicates, to improve lift in various phases of flight) wing type morphing with multi-nodal curvature, adapted to large aircraft for civil use, it was designed and investigated in the clean program. Sky is an innovative system which consists of robotic ribs, driven by electromechanical actuators which allow the modification of the wing. The project have run from concept to implementation in a fullscale model for pre-flight ground testing Pecoran, R. et. al. (2021). 
Bio-inspired aerial robots provide a large number of aerodynamic profiles that can be used for multiple mission objectives such as the Micro Aerial Aquatic Vehicle (AquaMAV) which provides a wing design with the possibility of retracting to make dives under the body, this water mechanism was inspired by the diving form of the Sulidae waterfowl (figure 4). The tests carried out in the wind tunnel showed that this folding wing has a good behavior in cruising conditions despite the design limitations generated by the folding mechanism, it is able to greatly decrease its own lift and drag when changing the shape allowing the vehicle to submerge smoothly from flight. Siddall, R.et. al. (2017)

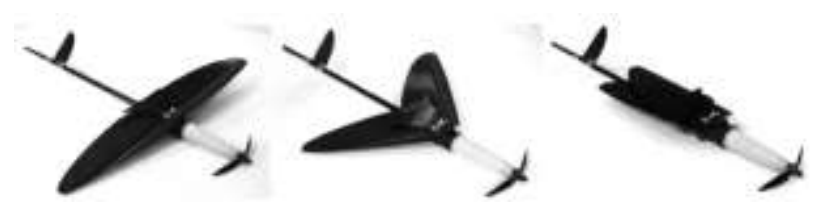

Figure 4 AquaMAV fuselage inspired by sulidae birds Siddall, R. et. al. (2017)

The great capacity that birds have during flight is the main inspiration to match not only the structure of the wing skeleton, but also the structure of the feathers as well as their distribution. A bio-pigeon-inspired morphing wing is used on a bionic feathered wing, with the aim of improving aerodynamic performance in an unmanned aerial vehicle (UAV). The wing structure is controlled by a morphing skeleton as shown in figure 5, this configuration allows modify its wing posture through a system of pulleys and a servo motor, similar to that of a pigeon during flight. Zhe, H. et. al. (2019).

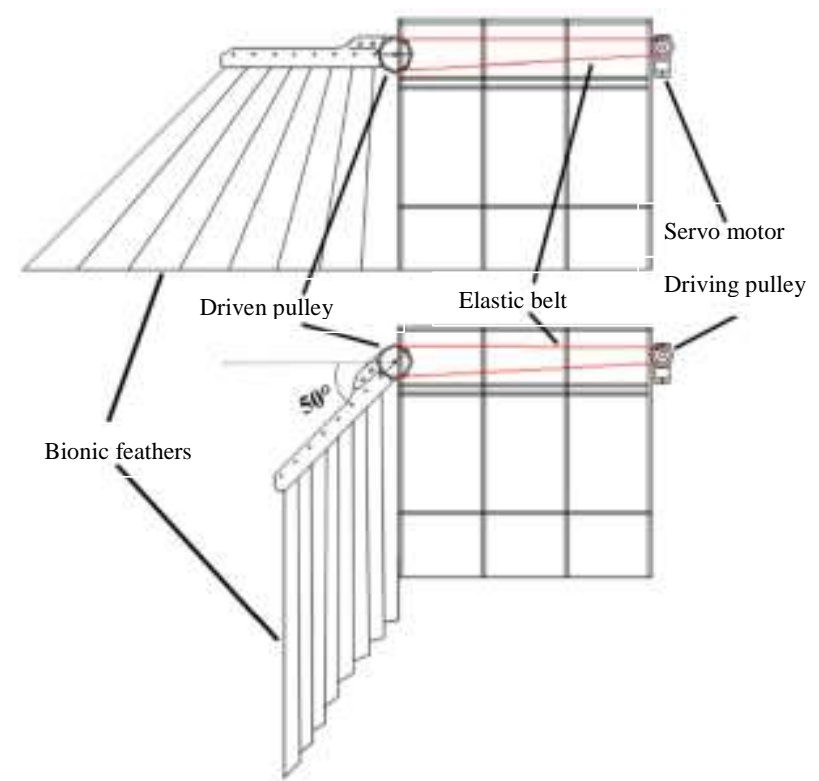

Figure 5 Bio-inspired morphing wing on a pigeon Zhe, H. et. al. (2019)
Twist morphing is a control technique which allows the rotation of the wing on an axis, which has a significant impact on the aerodynamic behavior of a lift surface without the need for major modifications to the wing, such as those associated with sweeping. or the variable wingspan required by complex and heavy mechanisms generally Jenett, B. et. al. (2017). Rotation of the tip is achieved by a flexible arm, the geometry of the arm is in relation to the actuator (servo motor) and the end effector (torque tube, which is located in the center of the wing and serves as the axis to achieve rotation) this allows achieving a favorable torque relationship, as shown in figure $6 \mathrm{Li}$, D. et. al. (2018).

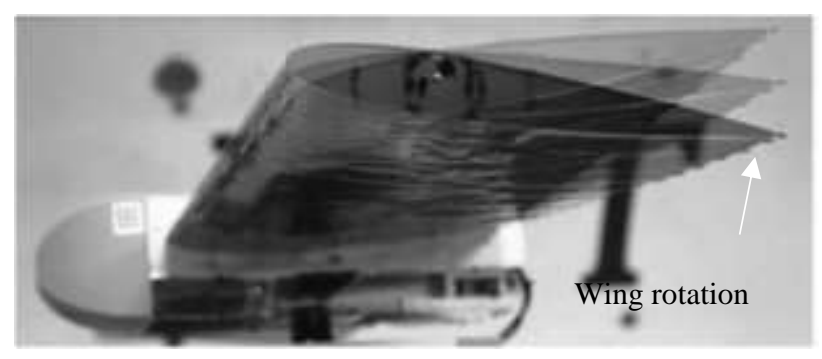

Figure 6 Reversible Assembled and Modular Wing Wind Tunnel Turning Jenett, B. et. al. (2017)

\section{Morphing wing modeling and analysis}

For structural analysis at component level, generally it is approached by two methods: the analytical homogenization method and the finite element method (FEM). Ripple shape optimization for better surface performance it is based on 2D thin beam elements. A homogenized model was achieved by taking into account the relationship between the Young's modulus of the cladding and the one of the composite corrugated core; also, by means of the finite element method for thin beams, it was possible to obtain a flexible but sufficiently rigid wing which changes its form and at the same time withstand aerodynamic loads Ermakova, $A$. et. al. (2017).

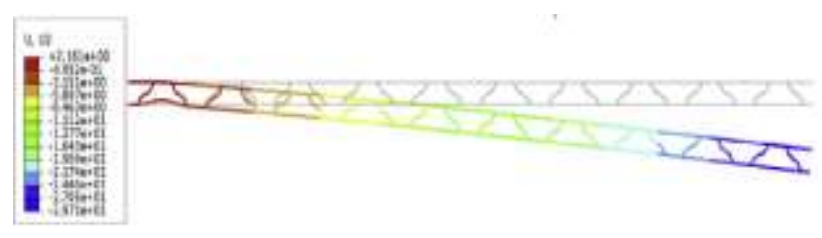

Figure 7 Bending of the clad corrugated surface based on the thin elements of the beam Ermakova, A. et. al. (2017) 
To calculate the equivalent tensile and flexural properties of the coated corrugated surfaces, two analytical solutions are reported. Because the elastomer cladding and the composite corrugated core are well bonded and have the same displacement, it can be neglected the deformation energy terms of the elastomer in contact with the fiberglass. Dayyani, I. et. al. (2013). A generic super element was also presented for a unit cell of an elastomer-clad corrugated core panel, motivated by morphing aircraft structures. The direct stiffness method and Castigliano's second theorem, together with the appropriate boundary conditions, were applied to obtain a matrix of the generic super element that captures the small deformation of curved beams Dayyani, I. et. al. (2014) and Li, D. et. al. (2018).

As for the aerodynamic methods applied in design of morphing wings there are a wide variety, and authors in the revised references establish that they are often used as a preliminary design tool, due to their high computational efficiency. There are several different tools for predicting aerodynamic performance based on linear methods and fluid dynamics (CFD). Linear methods are based on potential flow theory and are suitable for thin lift surfaces at small angles of attack, to simulate the aerodynamic behavior constantly used in optimizing morphing wing design.

The "XFOIL" software is a computational solver for 2D airfoils that combines a non-viscous panel method with a boundary layer formulation to predict the moment of lift, drag and pitch of airfoils in viscous flows Drela, M. et. al. (1989). Using "XFOIL" to perform fast and relatively accurate 2D constant flow simulations of different transformed configurations using a morphing wing has been reported by Lafountain, C. et. al. (2012). When comparing a linear method, "XFOIL", with the open source CFD solver "OpenFOAM", it was found that "XFOIL" provides very similar aerodynamic performance predictions than "OpenFOAM", but at a fraction of the computational cost, as reported by CFD solver Woods, B. et. al. (2014) and Li, D. et. al. (2018).

By comparing the CFD results versus wing morphing tests, a mesh was generated to provide sufficiently accurate results.
The numerical and experimental results obtained had shown agreement for the pressure distribution; however, it was not possible to accurately capture the drag reduction observed in experimental tests. Gabor, O. et. al. (2016) and Li, D. et. al. (2018).

With the use of CFD, a material was designed for a rigid but at the same time deformable lining which is composed of a multistable material; this was used in the trailing edge compared to conventional flaps, this material showed an increase in lift with the increase of the angle of flexion and so does the lift-resistance relationship with respect to the angle of attack, the part was designed based on an aerodynamic profile NACA0012 in which the rear wings were replaced by an intelligent bug edge Hao, F. et. al. (2020).

Another model using a NACA0012 profile in a two-dimensional model presented through CDF simulations and a dynamic mesh was used to test a flexible leading edge, this profile served as a point for comparison against conventional wings. The results showed that the downward deflection of the leading edge increases the angle of attack and pitch at the nose of the wing, the results were opposite for the upward deflection. Kan, Z. et. al. (2020).

A switch control proposal for the altitude movement of an aircraft with variable sweep wings was based on Q-learning. In this both the outer and inner part of the controller was designed, where the outer part was designed using the reverse method and the command filter technique to eliminate the problem of complexity explosion.

The control input switches go from outside to inside when there is analtitude error. For the interior part, the Qlearning algorithm is used for learning about the optimal commands when there are disturbances or unknown system matrices, it was shown that all the signals of the closed-loop system remain limited by the control method proposed in conjunction with the controller. Gong, L. et. al. (2020).

The design of a control system based on a full-scale wingtip actuation mechanism for an aircraft equipped with an aileron was proposed by Grigorie, T. et. al. (2020). 
The model is based on a mechanism with four actuators and placed inside the wing in two parallel lines as shown in figure 8 , each actuator uses a Brushless Direct Current electric motor coupled to a mechanical part, performing the conversion of the angular displacements to linear. This model was based on certain programmable EPOS drivers which were used to control the position Grigorie, T. et. al. (2020). In the tests that were carried out in the thatiwinnd tunnel, it was observed that the morphing technology improved the average position of the transition from laminar to turbulent flow in the wing, on the other hand it was observed that the transformed aerodynamic profile is benefited by an expansion of the laminar region over the entire surface of the deformable wing Grigorie, T. et. al. (2020).
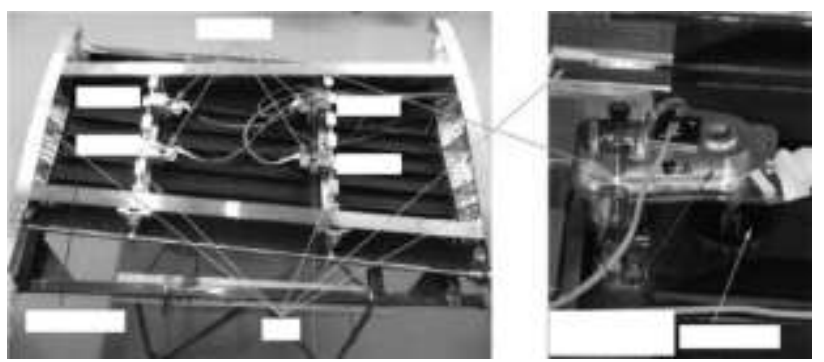

Figure 8 Actuator arrangement and motor location Griogorie, T. et al. (2020)

The design of a collapsible wing is made possible by an attitude controller called recoil with the desired angular acceleration function as shown in figure 9. The simulations and experimental results performed in the wind tunnel showed an increase of approximately $23 \%$ in body force production during wingbeat, Colorado J. et. al. (2013).

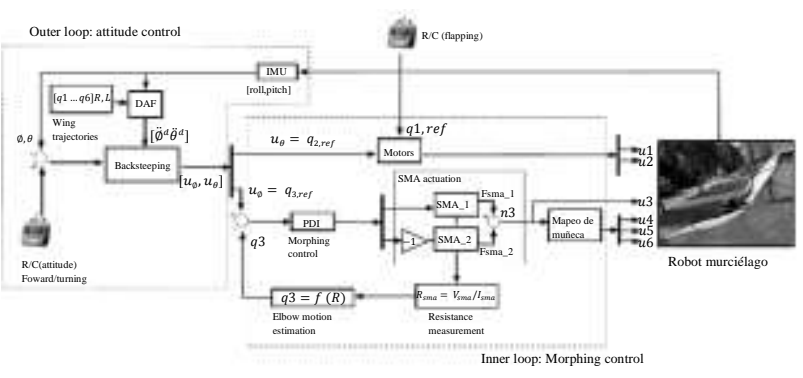

Figure 9 Flight control architecture scheme for bat robot Colorado, J. et. al. (2013)

\section{Conclusions}

Morphing type wings can improve the overall aerodynamic performance of an aircraft, these technologies are a great promise for large aircraft. Controlling the wing during flight like a bird naturally improves aerodynamic efficiency, as well as improves fuel burn and reduce emissions. There is a large number of works that propose novel concepts such as the ones shown in this research, others have been implemented in large aircraft and in real-scale projects, which allows researchers to put new technologies to the test.

However, there are still a large number of experiments to be carried out to scale in unmanned aerial vehicles, this is because the concepts must be taken from the level of material understanding to the development of new technologies, these also provide a suitable lowcost experimental platform for unconventional technologies.

The development of these concepts is very important for the industry because it can be optimized aircraft manufacturing and operating costs, which is why large aeronautical consortia are investing in full-scale projects such as SARITUS or Clean Sky, which are giving great advances in the implementation of these technologies for commercial use in large aircraft. The use of CFD and FEM can be implemented in the validation of technologies applied in mophing wings, a few years ago aircraft designers did not have much knowledge in these new transformation technologies. Today the knowledge of these has been spread exponentially, because they allow large scale projects which are expected to have a large implementation in the coming years

\section{References}

A. Ermakova, I. Dayyani,. (2017). Shape optimisation of composite corrugated morphing skins. Compos, Part B Eng. 115, 87-101 https://doi.org/10.1016/j.compositesb.2016.10.0 29

A.D. Shaw, I. Dayyani, M.I. Friswell,. (2015). Optimisation of composite corrugated skins for buckling in morphing aircraft, Compos. Struct. 119 ,

237.https://doi.org/10.1016/j.compstruct.2014.0 9.001 
A.Y.N. Sofla, S.A. Meguid, K.T. Tan, W.K. Yeo., (2010). Shape morphing of aircraft wing: status and challenges, Mater Des. 31 1284-1292. https://doi.org/10.1016/j.matdes.2009.09.011

Benjamin Jenett, Sam Calisch, Daniel Cellucci, Nick Cramer, Neil Gershenfeld, Sean Swei, and Kenneth C. Cheung. (2017). Digital Morphing Wing: Active Wing Shaping Concept Using Composite Lattice-Based Cellular Structures. Soft Robotics, 4, 33-48. https://doi.org/10.1089/soro.2016.0032

D. Lentink, U. K. Müller, E. J. Stamhuis, R. de Kat, W. van Gestel, L. L. M. Veldhuis, P. Henningsson, A. Hedenström, J. J. Videler \& J. L. van Leeuwen. (2007). How swifts control their glide performance with morphing wings. Nature, 446, 1082-1085. https://doi.org/10.1038/nature05733

Daochun Li, Shiwei Zhao, Andrea Da Ronch, Jinwu Xiang, Jernej Drofelnik, Yongchao Li, Lu Zhang, Yining Wu, Markus Kintscher, Hans Peter Monner, Anton Rudenko, Shijun Guo, Weilong Yin, Johannes Kirn, Stefan Storm \& Roeland De Breuker. (2018). A review of modelling and analysis of morphing wings. Progress in Aerospace Sciences, 100, 46-62. https://doi.org/10.1016/j.paerosci.2018.06.002.

Di Luca M., Mintchev S., Heitz G., Noca F. and Floreano D. (2017). Bioinspired morphing wings for extended flight envelope and roll control of small drones Interface Focus. 7 http://doi.org/10.1098/rsfs.2016.0092

Fengqian HAO, Tao TANG, Yuan GAO, Yimeng LI, Shenghui YI \& Jian LU. (2020). Continuous morphing trailing-edge wing concept based on multi-stable nanomaterial. Chinese Journal of Aeronautics https://doi.org/10.1016/j.cja.2020.03.041

H.P. Monner, M. Kintscher, T. Lorkowski, s Storm. (2009), Design of a smart droop-nose as leading-edge high-lift system for transportation aircraft, 50th AIAA/ASME/ASCE/AHS/ASC Structures, Structural Dynamics, and Materials Conference. https://doi.org/10.2514/6.20092128

H.P. Monner. (2001), Realization of an optimized wing camber by using formvariable flap structures, Aerosp. Sci. Technol. 5 445-455. https://doi.org/10.1016/S1270-9638(01)01118$\mathrm{X}$
Hans Peter Monner, Johannes Riemenschneider, Markus Kintscher (2012), Groundtest of a Composite Smart Droop-nose, 53rd AIAA/ASME/ASCE/AHS/ASC Structures, Structural Dynamics and Materials Conference. https://doi.org/10.2514/6.2012-1580

He, Z., Yin, M., \& Lu, Y. (2016). Tensor product model-based control of morphing aircraft in transition process. Proceedings of the Institution of Mechanical Engineers, Part G: Journal of Aerospace Engineering, 230, 378-391. https://doi.org/10.1177/0954410015591835

I. Dayyani, M.I. Friswell, E.I. Flores. (2014), A general super element for a curved beam, Int. J. Solid Struct. $51 \quad$ 2931-2939. https://doi.org/10.1016/j.ijsolstr.2014.04.021

I. Dayyani, M.I. Friswell, S. Ziaei-Rad, E.S. Flores. (2013), Equivalent models of composite corrugated cores with elastomeric coatings for morphing structures, Compos. Struct. 104 281292.https://doi.org/10.1016/j.compstruct.2013.0 4.034

J. Colorado, A. Barrientos, C. Rossi, C. Parra. (2013), Inertial attitude control of a bat-like morphing-wing air vehicle, Bioinspiration \& Biomimetics. 8 https://doi.org/10.1088/17483182/8/1/016001

J.H.S. Fincham, M.I. Friswell. (2015), Aerodynamic optimisation of a camber morphing aerofoil, Aerosp. Sci. Technol. 43 245-255

https://doi.org/10.1016/j.ast.2015.02.023

Lafountain C., Cohen K. and Abdallah S. (2012), Use of XFOIL in design of camber-controlled morphing UAVs. Comput. Appl. Eng. Educ., 20 673-680. https://doi.org/10.1002/cae.20437

Ligang GONG, Qing WANG, Changhua HU \& Chen LIU. (2020). Switching control of morphing aircraft based on Q-learning. Chinese Journal of Aeronautics, 33, 672-687. https://doi.org/10.1016/j.cja.2019.10.005.

M. Drela, XFOIL: an Analysis and Design System of Low Reynolds Number Aerofoils vol. 54, Springer-Verlag, 1989, pp. 1-12. https://doi.org/10.1007/978-3-642-84010-4_1 
M. Sinapius, H.P. Monner, M. Kintscher, J. Riemenschneider (2014), DLR's Morphing Wing Activities within the European Network, IUTAM $10, \quad 416-426$. https://doi.org/10.1016/j.piutam.2014.01.036

Maurizio Arena, Antonio Concilio \& Rosario Pecora. (2019). Aero-servo-elastic design of a morphing wing trailing edge system for enhanced cruise performance. Aerospace Science and Technology, 86, 215-235 https://doi.org/10.1016/j.ast.2019.01.020.

O.Ş. Gabor, A. Koreanschi, R.M. Botez, M. Mamou, Y. Mebarki. (2016), Numerical simulation and wind tunnel tests investigation and validation of a morphing wing-tip demonstrator aerodynamic performance, Aerosp. Sci. Technol. 53 136-153. https://doi.org/10.1016/j.ast.2016.03.014

Rosario Pecora. (2021). Morphing wing flaps for large civil aircraft: Evolution of a smart technology across the Clean Sky program. Chinese Journal of Aeronautics, 34, 13-28. https://doi.org/10.1016/j.cja.2020.08.004.

S. Barbarino, E.I. Saavedra Flores, R.M. Ajaj, I. Dayyani, M.I. Friswell. (2014), A review on shape memory alloys with applications to morphing aircraft, Smart Mater Struc. 23 https://doi.org/10.1088/0964-1726/23/6/063001 S. Daynes, P.M. Weaver. (2013), Stiffness tailoring using prestress in adaptive composite structures, Compos. Struct. 106, 282287https://doi.org/10.1016/j.compstruct.2013.0 5.059

Siddall Robert, Ortega Ancel Alejandro and Kovač Mirko 2017ind and water tunnel testing of a morphing aquatic micro air vehicle Interface Focus.7 http://doi.org/10.1098/rsfs.2016.0085

Teodor Lucian GRIGORIE, Shehryar KHAN, Ruxandra Mihaela BOTEZ, Mahmoud MAMOU \& Youssef MÉBARKI. (2020). Design and experimental testing of a control system for a morphing wing model actuated with miniature BLDC motors. Chinese Journal of Aeronautics, 33, 1272-1287. https://doi.org/10.1016/j.cja.2019.08.007.
Woods, B. K., Bilgen, O., \& Friswell, M. I. (2014). Wind tunnel testing of the fish bone active camber morphing concept. Journal of Intelligent Material Systems and Structures, 25, 772-785.

https://doi.org/10.1177/1045389X14521700

Xiaojun GU, Kaike YANG, Manqiao WU, Yahui ZHANG, Jihong ZHU \& Weihong ZHANG. (2021). Integrated optimization design of smart morphing wing for accurate shape control. Chinese Journal of Aeronautics, 34, 135-147

https://doi.org/10.1016/j.cja.2020.08.048.

Z. Lyu, J.R.R.A. Martins. (2015), Aerodynamic shape optimisation of an adaptive morphing trailing-edge wing, J. Aircraft 52, 1951-1970 https://doi.org/10.2514/1.C033116

Zhe Hui, Yang Zhang \& Gang Chen,. (2019). Aerodynamic performance investigation on a morphing unmanned aerial vehicle with bioinspired discrete wing structures. Aerospace Science and Technology, 95 https://doi.org/10.1016/j.ast.2019.105419

Zheng Min, Vu Khac Kien \& Liew J.Y. Richard (2010) Aircraft morphing wing concepts with radical geometry change, The IES Journal Part A: Civil \& Structural Engineering,3:3, 188-195 https://doi.org/10.1080/19373261003607972

Zi KAN, Daochun LI , Tong SHEN, Jinwu XIANG \& Lu ZHANG. (2020). Aerodynamic characteristics of morphing wing with flexible leading-edge. Chinese Journal of Aeronautics, 33 ,

2610-2619 https://doi.org/10.1016/j.cja.2020.03.012.

$\mathrm{Zi}$ KAN, Daochun, LI Jinwu XIANG \& Chunxiao CHENG. (2020). Delaying stall of morphing wing by periodic trailing-edge deflection. Chinese Journal of Aeronautics, 33, 493-500.

https://doi.org/10.1016/j.cja.2019.09.028. 